\title{
Site-specific DOTA/europium-labeling of recombinant human relaxin-3 for receptor-ligand interaction studies
}

Wei-Jie Zhang ${ }^{1 \#}$, Xiao Luo ${ }^{1 \#}$, Ya-Li Liu ${ }^{2}$, Xiao-Xia Shao ${ }^{1}$, John D. Wade ${ }^{3,4 *}$, Ross A.D. Bathgate ${ }^{3,5 *}$, Zhan-Yun Guo ${ }^{1 *}$

${ }^{1}$ Institute of Protein Research, College of Life Sciences and Technology, Tongji University, Shanghai 200092, China

${ }^{2}$ Central Laboratory, Shanghai East Hospital, Tongji University School of Medicine, Shanghai 200120, China

${ }^{3}$ Florey Neuroscience Institutes, The University of Melbourne, Victoria 3010 , Australia

${ }^{4}$ School of Chemistry, The University of Melbourne, Victoria 3010, Australia

${ }^{5}$ Department of Biochemistry and Molecular Biology, The University of Melbourne, Victoria 3010, Australia

\# These authors contributed equally to this work.

*Corresponding authors:

Ross A. D. Bathgate

Tel: +61-3-8344-6548; Fax: +61-3-9348-1707; e-mail: ross.bathgate@ florey.edu.au

John D. Wade

Tel: +61-3-8344-7258; Fax: +61-3-9348-1707; e-mail: john.wade@florey.edu.au

Zhan-Yun Guo

Tel: +86-21-65988634; Fax: +86-21-65898403; e-mail: zhan-yun.guo@ tongji.edu.cn 
Abstract Relaxin-3 (also known as INSL7) is a recently identified neuropeptide belonging to the insulin/relaxin superfamily. It has putative roles in the regulation of stress responses, food intake, and reproduction by activation of its cognate G-protein coupled receptor RXFP3. It also binds and activates the relaxin family peptide receptors RXFP1 and RXFP4 in vitro. To obtain a europium-labeled relaxin-3 as tracer for studying the interaction of these receptors with various ligands, in the present work we propose a novel site-specific labeling strategy for the recombinant human relaxin-3 that has been previously prepared in our laboratory. First, the $\mathrm{N}$-terminal $6 \times$ His-tag of the single-chain relaxin-3 precursor was removed by Aeromonas aminopeptidase and all of the primary amines of the resultant peptide were reversibly blocked by citroconic anhydride. Second, the A-chain N-terminus of the blocked peptide was released by endoproteinase Asp-N cleavage that removed the linker peptide between the B- and A-chains. Third, an alkyne moiety was introduced to the newly released A-chain $\mathrm{N}$-terminus by reaction with the highly active primary amine-specific N-hydroxysuccinimide ester. Fourth, after removal of the reversible blockage under mild acidic condition, europium-loaded DOTA with an azide moiety was introduced to the two-chain relaxin-3 carrying the alkyne moiety through click chemistry. By using this site-specific labeling strategy, homogeneous monoeuropium-labeled human relaxin-3 could be obtained with good overall yield. In contrast, conventional random labeling resulted in a complex mixture that was poorly resolved because human relaxin-3 has four primary amine moieties that all react with the modification reagent. Both saturation and competition binding assays demonstrated that the DOTA/ $\mathrm{Eu}^{3+}$-labeled relaxin-3 retained high binding affinity for human RXFP3, RXFP4, and RXFP1 and was therefore a suitable non-radioactive and stable tracer to study the interaction of various natural or designed ligands with these receptors. By using this site-specific labeling strategy, other functional probes, such as fluorescent dyes, biotin, or nanoparticles could also be introduced to the A-chain $\mathrm{N}$-terminal of the recombinant human relaxin-3. Additionally, we improved the time-resolved fluorescence assay for the DOTA-bound europium ion which paves the way for the use of DOTA as a lanthanide chelator for protein and peptide labeling in 
future studies.

Keywords Click chemistry $\cdot$ Europium $\cdot$ INSL7 $\cdot$ Relaxin-3 $\cdot$ Site-specific labeling

\section{Abbreviations}

BSA Bovine serum albumin

DOTA 1,4,7,10-tetraazacyclododecane-1,4,7,10-tetraacetic acid

DMSO Dimethyl sulfoxide

HPLC High performance liquid chromatography

NHS N-hydroxysuccinimide

PCR Polymerase chain reaction

PEG Polyethylene glycol;

TBTA Tris[(1-benzyl-1H-1,2,3-triazol-4-yl)methyl]amine

t-BuOH tert-butyl alcohol

TFA Trifluoroacetic acid

TRF Time-resolved fluorescence

UV Ultra-violet 


\section{Introduction}

Relaxin-3 (also known as INSL7) is a new member of the insulin/relaxin superfamily (Shabanpoor et al. 2009; Smith et al. 2011b; Tanaka 2010). It was identified in 2002 by a search of the human genome based on the cysteine pattern of the B-chain of the insulin superfamily (Bathgate et al. 2002; Burazin et al. 2002). Relaxin-3 is predominantly expressed in the nucleus incertus of the brain (Bathgate et al. 2002; Burazin et al. 2002; Ma et al. 2009; Silvertown et al. 2010; Tanaka et al. 2005). Administration of exogenous relaxin-3 in rats (Banerjee et al. 2010; Hida et al. 2006; McGowan et al. 2005; McGowan et al. 2006; McGowan et al. 2007; McGowan et al. 2008; Tanaka et al. 2005; Watanabe et al. 2011a) and gene knockout experiments (Smith et al. 2009a; Smith et al. 2009b; Smith et al. 2011a; Watanabe et al. 2011b) showed that the peptide is involved in the regulation of the stress response, food intake, reproduction, as well as arousal and exploratory behaviors. The biological function of relaxin-3 is mediated by its cognate receptor RXFP3 that is also primarily expressed in the brain (Liu et al. 2003b). Relaxin-3 also binds and activates RXFP1 and RXFP4 in vitro, the cognate receptors of relaxin and INSL5 respectively (Hsu et al. 2002; Liu et al. 2003a; Liu et al. 2005; Sudo et al. 2003). Since relaxin-3 is the agonist of three of four known relaxin-family peptide receptors (RXFP1-4), it is a good model for studying the interaction of these G-protein coupled receptors with relaxin-family peptides. For the receptor-ligand interaction studies, a labeled tracer that can be easily and sensitively detected is needed. Conventionally, radionuclides,

such as ${ }^{125} \mathrm{I}$, are used to label proteins and peptides. However, the use of radionuclides has drawbacks, such as their short-half life, high cost, and safety concerns. In recent years, lanthanides such as $\mathrm{Eu}^{3+}, \mathrm{Tb}^{3+}$, and $\mathrm{Sm}^{3+}$ have been used for protein and peptide labeling due to their highly sensitive time-resolved fluorescence (TRF) and non-radioactive property (Selvin 2002).

To obtain a europium-labeled relaxin-3 as nonradioactive and stable tracer for receptor-ligand interaction studies, in the present work we propose a novel site-specific labeling strategy for the recombinant human relaxin-3 that has been 
previously prepared in our laboratory (Luo et al. 2010). By using this strategy, homogeneous DOTA/Eu ${ }^{3+}$-labeled relaxin-3 retaining high receptor binding affinity could be obtained with good overall yield (typically 50-100 $\mu \mathrm{g}$ of labeled peptide from $1.0 \mathrm{mg}$ of folded relaxin-3 precursor). In contrast, conventional random labeling approach resulted in a complex labeling mixture that was poorly resolved on rp-HPLC because human relaxin-3 has four active primary amine moieties (two N-terminus $\alpha$-amines and two internal side-chain $\varepsilon$-amines) that all react with the labeling reagent.

\section{Materials and methods}

Materials

The Agilent reverse-phase columns (analytical column: Zorbax 300SB-C18, $4.6 \mathrm{~mm} \times$ $250 \mathrm{~mm}$; semi-preparative column: Zorbax 300SB-C18, $9.4 \mathrm{~mm} \times 250 \mathrm{~mm}$ ) were used in the experiments. The peptide was eluted from the C18 reverse-phase column by an acidic acetonitrile gradient composed of solvent A and solvent B. Solvent A was $0.1 \%$ aqueous TFA, and solvent $\mathrm{B}$ was acetonitrile containing $0.1 \%$ TFA. The elution gradient was listed as follows: 0 min, 10\% solvent B; 3 min, 10\% solvent B; 53 min, $60 \%$ solvent $\mathrm{B} ; 55 \mathrm{~min}, 100 \%$ solvent $\mathrm{B} ; 56 \mathrm{~min}, 100 \%$ solvent $\mathrm{B}, 60 \mathrm{~min}, 10 \%$ solvent B. The flow rate for analytical column was $0.5 \mathrm{ml} / \mathrm{min}$, and that for semi-preparative column was $1.0 \mathrm{ml} / \mathrm{min}$. The eluted peptide was detected by UV absorbance at both $280 \mathrm{~nm}$ and $214 \mathrm{~nm}$.

6×His-tag removal by Aeromonas aminopeptidase

The recombinant single-chain human relaxin-3 precursor $(6 \times$ His-relaxin-3) was prepared according to our previous procedure (Luo et al. 2010). The refolded precursor was dissolved in the aminopeptidase digestion buffer (50 mM Tris- $\mathrm{HCl}, 1.0$ 
$\mathrm{M}$ guanidine chloride, $\mathrm{pH} 8.0$ ) at the final concentration of $\sim 5 \mathrm{mg} / \mathrm{ml}$. Then Aeromonas aminopeptidase (Sigma-Aldrich, St. Louis, USA) stock solution was added (1 unit enzyme versus $2-3 \mathrm{mg}$ peptide) to remove the $\mathrm{N}$-terminus $6 \times$ His-tag. The digestion was carried out at $30{ }^{\circ} \mathrm{C}$ overnight. Thereafter, the digestion mixture was acidified by TFA and subjected to C18 rp-HPLC. The eluted peptide fraction was manually collected, lyophilized, and subjected to mass spectrometry analysis.

Reversible primary amine blockage by citroconic anhydride

The above single-chain relaxin-3 without $6 \times$ His-tag was suspended in the blocking buffer (100 mM sodium phosphate, $\mathrm{pH} 8.0$ ) at a final concentration of $\sim 5 \mathrm{mg} / \mathrm{ml}$ $(\sim 730 \mu \mathrm{M})$. The freshly prepared citraconic anhydride (Sigma-Aldrich, St. Louis, USA) stock solution (in DMSO) was then added to a final concentration of $20 \mathrm{mM}$. The $\mathrm{pH}$ value of the reaction mixture was monitored and kept at 7-8 by adding $1.0 \mathrm{M}$ $\mathrm{NaOH}$ solution. The blocking reaction was carried out at $4{ }^{\circ} \mathrm{C}$ for $30 \mathrm{~min}$. Thereafter, the excess amount of blocking reagent was removed by gel filtration (Sephadex G-25 column) that was pre-equilibrated by $10 \mathrm{mM}$ Tris- $\mathrm{HCl}$ buffer $(\mathrm{pH} 8.0)$. The blocked single-chain relaxin-3 was eluted from the gel filtration column, manually collected, and lyophilized.

Endoproteinase Asp-N digestion

The above lyophilized blocked single-chain relaxin-3 (containing Tris-HCl salt) was dissolved by adding an appropriate amount of water (the final peptide concentration was $\sim 5 \mathrm{mg} / \mathrm{ml}$ ). Endoproteinase Asp-N (Sigma-Aldrich, St. Louis, USA) solution was then added (mass ratio of peptide to enzyme 5000:1) to remove the linker peptide between the B- and A-chains. The digestion was carried out at $30^{\circ} \mathrm{C}$ overnight. After digestion, the sample was applied to a gel filtration column (Sephadex G-25) that was pre-equilibrated with $10 \mathrm{mM}$ sodium phosphate buffer $(\mathrm{pH} 8.0)$. The peptide was eluted from the column using $10 \mathrm{mM}$ phosphate buffer ( $\mathrm{pH} 8.0$ ), manually collected, 
and lyophilized.

Alkyne-moiety introduction and deblocking

The above lyophilized blocked two-chain human relaxin-3 (containing phosphate salt) was dissolved by adding an appropriate amount of water to a final concentration of $\sim 2$ $\mathrm{mg} / \mathrm{ml}(\sim 350 \mu \mathrm{M})$. Thereafter, the stock solution (in DMSO) of acetylene-PEG4-NHS ester (Click Chemistry Tools, Macon, USA) was added to the final concentration of $5.0 \mathrm{mM}$ to irreversibly modify the newly released A-chain N-terminus. The modification reaction was carried out at $25{ }^{\circ} \mathrm{C}$ for $3 \mathrm{~h}$. Thereafter, $1.0 \mathrm{M}$ Tris- $\mathrm{HCl}$ stock solution ( $\mathrm{pH} 7.4$ ) was added to a final concentration of $50 \mathrm{mM}$ to react with the excess amount of the modification reagent. Subsequently, the mixture was 20 -fold diluted into $10 \%$ aqueous acetic acid solution to remove the citroconic acid blockage. The deblocking reaction was carried out at $25{ }^{\circ} \mathrm{C}$ for $36 \mathrm{~h}$. Finally, the deblocking mixture was subjected to C18 rp-HPLC and was eluted by an acidic acetonitrile gradient. The eluted peptide fraction was manually collected, lyophilized, and analyzed by mass spectrometry.

Introduction of DOTA-bound europium ion through click chemistry

To form the DOTA/Eu ${ }^{3+}$ complex, $\mathrm{EuCl}_{3}$ (Sigma-Aldrich, St. Louis, USA) solution (80 $\mathrm{mM}$ in water) was mixed with an equal volume of azido-mono-amide-DOTA (Macrocyclics, Dallas, USA) solution (40 $\mathrm{mM}$ in water). The $\mathrm{pH}$ of the mixture was then adjusted to $\sim 7$ by adding $\mathrm{NaOH}$ solution (checked by $\mathrm{pH}$ paper). The mixture was kept at room temperature for 10-20 min to allow the complex to form and could then be stored at $-20{ }^{\circ} \mathrm{C}$ for several months. To form the CuBr/TBTA complex, one volume of fresh $\mathrm{CuBr}$ (Sigma-Aldrich, St. Louis, USA) solution (100 $\mathrm{mM}$ in DMSO/t-BuOH solvent, vol/vol 3:1, containing $10 \mathrm{mM}$ ascorbate) was mixed with two volumes of TBTA (Sigma-Aldrich, St. Louis, USA) solution (100 mM in DMSO/t-BuOH solvent, vol/vol 3:1). The CuBr/TBTA complex should be freshly 
prepared. The above lyophilized two-chain relaxin-3 carrying an alkyne moiety at the A-chain N-terminus was dissolved in $\mathrm{DMSO} / \mathrm{t}-\mathrm{BuOH}$ solvent (vol/vol 3:1) at a final concentration of $5-10 \mathrm{mg} / \mathrm{ml}$. Thereafter, the above DOTA/Eu ${ }^{3+}$ complex (molar ratio of peptide to DOTA at 1:5) and CuBr/TBTA complex (molar ratio of peptide to $\mathrm{CuBr}$ at $\sim 1: 10)$ was added to initiate the click chemistry reaction that was carried out at 20 ${ }^{\circ} \mathrm{C}$ overnight. Thereafter, the reaction solution was diluted by water, acidified to pH3.0, and applied to C18 rp-HPLC. The DOTA/Eu ${ }^{3+}$-labeled peptide was eluted from the $\mathrm{C} 18$ reverse-phase column by an acidic acetonitrile gradient, manually collect, lyophilized, and analyzed by mass spectrometry.

Time-resolved fluorescence measurement for the DOTA-bound europium ion

An appropriate amount of the DOTA/Eu $u^{3+}$-labeled relaxin-3 sample was added into a 96-well clear plate, then $50 \mu \mathrm{l}$ of $2.0 \mathrm{M}$ aqueous $\mathrm{HCl}$ solution was added to dissociate the europium ion from the DOTA chelator. The dissociation was carried out at $37{ }^{\circ} \mathrm{C}$ overnight in a sealed humid chamber. Subsequently, $\sim 50 \mu \mathrm{l}$ of neutralizing solution (2.0 $\mathrm{M}$ glycine, $2.0 \mathrm{M} \mathrm{NaOH}$ ) was added and mixed to adjust the $\mathrm{pH}$ value to 3-4. The accurate volume of the neutralizing solution should be carefully checked according to the $\mathrm{pH}$ value of the neutralized solution. Then, $150 \mu \mathrm{l}$ of enhancer solution (PerkinElmer, Waltham, MA, USA) was immediately added and well mixed. After 2-3 $\mathrm{h}$ gentle shaking, the time-resolved fluorescence was measured on a Spectramax M5 plate reader (at Tongji University) or on a Victor 3 plate reader (at Florey Institute).

Saturation binding of the DOTA/Eu ${ }^{3+}$-labeled relaxin-3 with relaxin family peptide receptors

The saturation binding assays on human RXFP1 (at Florey Institute) were carried out as described previously (Shabanpoor et al. 2008) while those on human RXFP3 and human RXFP4 (at Tongji University) were carried out according to a slightly modified procedure. The genes of human RXFP3 and human RXFP4 were PCR 
amplified using human genomic DNA as template since they do not contain introns. The amplified DNA fragments were then cloned into the pcDNA6 vector and sequenced. Thereafter, the expression constructs were transfected into HEK293T cells using the transfection reagent Lipofectmine 2000 (Invitrogen, Carlsbad, CA, USA) according to the users' manual. At the second day, the transfected cells were trypsinized and seeded onto 96-well plates. After the cells grew to near confluency (24-48 h), the medium was removed and the saturation binding solution $(200 \mu \mathrm{l} /$ well $)$ containing different concentrations of the DOTA/Eu ${ }^{3+}$-relaxin-3 was added. The binding solution was serum-free DMEM/F-12 medium plus $1 \%$ BSA. After incubation at $20-22{ }^{\circ} \mathrm{C}$ for $2 \mathrm{~h}$, the assay solution was removed and the cells were washed with cold wash solution (serum-free DMEM/F-12 medium, $200 \mu \mathrm{l} /$ well) twice. Thereafter, $2 \mathrm{M} \mathrm{HCl}$ solution $(50 \mu \mathrm{l} /$ well $)$ was added and the plate was incubated at $37{ }^{\circ} \mathrm{C}$ overnight in a sealed humid chamber to dissociate $\mathrm{Eu}^{3+}$ from DOTA. The TRF was measured according to the above improved procedure. The non-specific binding value was obtained by competition with $1.0 \mu \mathrm{M}$ of mature human relaxin-3. The specific binding data were fitted with the one-site binding model by using the software SigmaPlot 10.0

Competition receptor binding using DOTA/Eu ${ }^{3+}$-labeled relaxin-3 as tracer

The competition binding assays on human RXFP1 (at Florey Institute) were carried out as described previously (Shabanpoor et al. 2008) while those on human RXFP3 and human RXFP4 (at Tongji University) were carried out according to a slightly modified procedure. The HEK293T cells transiently expressing RXFP3 or RXFP4 were prepared according to the description above. For the competitive binding assay, the competition binding solution $(200 \mu \mathrm{l} /$ well $)$ containing constant concentration of DOTA/Eu ${ }^{3+}$-relaxin-3 and varied concentrations of competitor was added. The binding solution was serum-free DMEM/F12 medium with 1\% BSA. After incubation at $20-22{ }^{\circ} \mathrm{C}$ for $2 \mathrm{~h}$, the competition binding solution was removed and the cells were washed with cold wash solution (serum-free DMEM/F-12 medium, $200 \mu \mathrm{l} /$ well) twice. 
Thereafter, TRF was measured according to the improved procedure. The non-specific binding value was obtained by competition with $1.0 \mu \mathrm{M}$ of competitor. The specific competition binding data were fitted by sigmoidal curves using the software SigmaPlot 10.0.

\section{Results}

Rationale of a site-specific labeling strategy for the recombinant human relaxin-3

In the previous work (Luo et al. 2010) we designed and recombinantly expressed a single-chain relaxin-3 precursor (Figure 1A) that can be enzymatically converted to mature two-chain human relaxin-3 (Figure 1B). To obtain europium-labeled relxin-3 as tracer for ligand-receptor interaction studies, we first tried random labeling using the mature recombinant human relaxin-3 and the commercially available labeling reagent DELFIA Eu-DTPA ITC chelate. Unfortunately, random labeling resulted in a very complex labeling mixture that was poorly resolved on rp-HPLC (data not shown) because human relaxin-3 has four primary amine moieties that all react with the labeling reagent. This phenomenon has also been observed in the random labeling of human INSL3 that has three primary amine moieties (Shabanpoor et al. 2008). Therefore, we proposed a novel site-specific labeling strategy for the recombinant human relaxin-3 (Figure 1C). First, the N-terminal $6 \times$ His-tag of the refolded $6 \times$ His-relaxin-3 precursor was removed by Aeromonas amimopeptidase that can remove residues one by one from the N-terminus, but cannot cleave Glu or Asp residue. The resultant single-chain relaxin-3 without the $6 \times$ His-tag was designated as I-1. Second, the N-terminal $\alpha$-amine and two internal $\varepsilon$-amines of I-1 were reversibly blocked by citroconic moieties, and the resultant blocked peptide was designated as I-2. The citroconic modification is stable under neutral and alkaline condition, but can be readily removed under mild acidic condition ( $\mathrm{pH} 3-4)$. Third, I-2 was treated by endoproteinase Asp-N to remove the linker peptide between the B- and A-chains, and 
releasing a new A-chain N-terminus. The blocked two-chain relaxin-3 was designated as I-3. Fourth, the newly released A-chain N-terminus in I-3 was irreversibly modified by acetylene-PEG4-NHS ester that carries a terminal alkyne moiety and a highly active primary amine-specific NHS ester moiety. The resultant intermediate carrying an alkyne moiety was designated as I-4. Fifth, the citraconic blockage in I-4 was removed under acidic condition, and the resultant deblocked intermediate carrying an alkyne-moiety was designated as I-5. Sixth, various functional moieties, such as metal ion-chelators, biotin, fluorescent dyes, or nanoparticles, with an attached azido moiety could be introduced to I-5 through $\mathrm{Cu}^{+}$-catalyzed cycloaddition between the alkyne moiety and the azido moiety. In the present work, europium ion bound with the extremely tight lanthanide chelator DOTA was introduced to the recombinant human relaxin-3. Due to the sensitive TRF of the europium ion, the DOTA/Eu ${ }^{3+}$-labeled relaxin-3 was expected to be a suitable non-radioactive tracer for studying the interaction of relaxin-family peptide receptors with their various natural or designed ligands.

$6 \times$ His-tag removal, reversible blocking and endoproteinase Asp- $\mathrm{N}$ digestion

The recombinant single-chain $6 \times$ His-relaxin-3 precursor was prepared according to our previous procedure (Luo et al. 2010). Thereafter, the refolded precursor was subjected to Aeromonas aminopeptidase digestion in order to remove the $\mathrm{N}$-terminal $6 \times$ His-tag. As analyzed by C18 rp-HPLC (Figure 2), a major peak (indicated by a star) appeared after digestion. Its measured molecular mass was 7691.0, that was consistent with the expected value (7691.6) of the single-chain relaxin-3 without $6 \times$ His-tag (I-1 in Figure 1C). Next, the three primary amines of the single-chain relaxin-3 (I-1), including one $\mathrm{N}$-terminus $\alpha$-amine and two internal $\varepsilon$-amines, were reversibly blocked by citroconic moieties (II-2 in Figure 1C). To prevent non-specific modification, the reaction was carried out at low temperature. The excess amount of the modification reagent was removed by gel filtration, and the peptide fraction eluted by neutral Tris- $\mathrm{HCl}$ solution was then lyophilized, re-dissolved, and digested by 
endoproteinase Asp-N in order to remove the linker peptide between the B- and A-chains (I-3 in Figure 1C). The enzyme Asp-N showed higher activity in Tris solution than in phosphate solution, so Tris- $\mathrm{HCl}$ solution was used for digestion. After digestion, the peptide was exchanged into phosphate buffer that was compatible with the next step amine-specific modification.

Introduction of an alkyne-moiety to the A-chain N-terminus of the recombinant relaxin-3

After endoproteinase Asp-N digestion, the newly released A-chain $\mathrm{N}$-terminus of the blocked two-chain relaxin-3 was irreversibly modified by primary amine-specific modification reagent acetylene-PEG4-NHS ester. Through this modification, a terminal alkyne moiety was irreversibly introduced (I-4 in Figure 1C). Thereafter, the acid labile citroconic blockage was removed in acid solution (I-5 in Figure 1). As analyzed by C18 rp-HPLC (Figure 3), a major peak (indicated by a star) appeared on rp-HPLC after deblocking. Its measured molecular mass (6029.0) was consistent with the expected value (6028.0) of the two-chain relaxin-3 carrying a single alkyne moiety (I-5 in Figure 1C). The alkyne moiety was a uniquely active group in this intermediate that could react with an azido moiety through click chemistry that was first introduced by K. Barry Sharpless in 2001 (Kolb et al. 2001) and is now widely used for labeling of biomolecules due to its bioorthogonal properties.

Introduction of DOTA-bound europium ion to human relaxin-3 through click chemistry

The reagent azido-mono-amide-DOTA was preloaded with $\mathrm{Eu}^{3+}$ through incubation with $\mathrm{EuCl}_{3}$ solution. This prevented chelation of $\mathrm{Cu}(\mathrm{I})$ ion which is used in the click chemistry reaction. After the $\mathrm{Cu}^{+}$-catalyzed cycloaddition, a major peak (indicated by a star) appeared on C18 rp-HPLC that was eluted by the acidic acetonitrile gradient (Figure 4a). This major peak was manually collected, lyophilized, and analyzed by 
mass spectrometry. As shown in Figure 4b, its measured molecular mass (6664.0) was consistent with the theoretical value (6666.5) of the mono-europium labeled relaxin-3, suggesting that the europium ion did not dissociate from DOTA even when eluted by the acidic acetonitrile gradient (0.1\% TFA). The yield was typically 50-100 $\mu \mathrm{g}$ of DOTA/Eu ${ }^{3+}$-labeled peptide from $1.0 \mathrm{mg}$ of the folded relaxin-3 precursor.

Optimizing the time-resolved fluorescence measurement of the DOTA-bound europium ion

The tight binding between $\mathrm{Eu}^{3+}$ and DOTA simplified the purification of the labeled relaxin-3 since the labeled peptide could be eluted by the conventionally used acidic solvent from rp-HPLC without loss of europium ion. However, the tight binding made the time-resolved fluorescence (TRF) measurement difficult because dissociation of europium from DOTA is a prerequisite for this measurement. According to a previous report (De Silva et al. 2010), we used 2.0 M aqueous $\mathrm{HCl}$ to dissociate the europium ion from DOTA before TRF measurement. However, we found that the reported subsequent neutralization procedure (De Silva et al. 2010) by $2.0 \mathrm{M} \mathrm{NaOH}$ solution was problematic during our work. The TRF measurement was very sensitive to $\mathrm{pH}$ but the enhancer solution is a poor buffer, so a little more or less of the neutralizing $\mathrm{NaOH}$ solution significantly changed the $\mathrm{pH}$ of the neutralized solution. Therefore, the TRF measurement could not be repeated when we used the manual pipettor to add the dissociation and neutralization solutions (data not shown). So we decided to use a reagent with high buffering capacity at $\mathrm{pH} 3-4$ to stabilize the $\mathrm{pH}$ of the neutralized solution. As shown in Figure 6, when a high concentration of glycine was included in the neutralizing solution (2.0 M NaOH, 2.0 M glycine), the TRF assay showed good reproducibility. The measured TRF values of the europium standard subjected to acidification/neutralization (filled circles) or not (open circles) were similar when the plateau was reached, but a longer time $(2-3 \mathrm{~h})$ was needed to reach the plateau for the acidification/neutralization-treated sample. For the DOTA/Eu ${ }^{3+}$-labeled relaxin-3, the TRF could be detected only after the acidification/neutralization treatment (filled 
squares). According to the measured Eu quantity and the relaxin-3 peptide quantity estimated from the HPLC peak area, the molar ratio of europium ion to relaxin-3 peptide was about 1:1 which was consistent with the result of mass spectrometry analysis.

Saturation binding of the DOTA/Eu ${ }^{3+}$-labeled relaxin-3 with relaxin family peptide receptors

To test whether the DOTA/Eu ${ }^{3+}$-labeled relaxin-3 retained receptor-binding activity, we first carried out saturation binding assays using the transiently expressed receptors on HEK293T cells as the receptor source. As shown in Figure 6A, the binding curve of the labeled relaxin-3 on human RXFP3, the cognate receptor of relaxin-3, was typically hyperbolic. The measured data could be well fitted by the hyperbolic ligand binding function $\mathrm{Y}=\mathrm{B}_{\max } \mathrm{X} /\left(\mathrm{K}_{\mathrm{d}}+\mathrm{X}\right)$. The calculated $\mathrm{K}_{\mathrm{d}}$ for RXFP3 was $1.9 \pm 0.2 \mathrm{nM}$, suggesting the DOTA/Eu ${ }^{3+}$-labeled peptide could bind RXFP3 with high affinity despite the presence of the large DOTA/Eu ${ }^{3+}$ moiety. As shown in Figure 6B, the labeled relaxin-3 could also bind to human RXFP4, the cognate receptor of INSL5, in a hyperbolic manner. The calculated $\mathrm{K}_{\mathrm{d}}$ for RXFP4 was $5.4 \pm 0.8 \mathrm{nM}$. As shown in Figure $6 \mathrm{C}$, the labeled relaxin-3 could also bind to human RXFP1, the cognate receptor of relaxin, in a hyperbolic manner. The calculated $K_{d}$ for RXFP1 was $15.9 \pm 2.3 \mathrm{nM}$.

Competition receptor binding using DOTA/Eu ${ }^{3+}$-labeled relaxin-3 as tracer

The above saturation binding assays showed that the DOTA/Eu ${ }^{3+}$-labeled relaxin-3 retained binding affinity for RXFP3, RXFP4, and RXFP1. Therefore, we used the labeled peptide as tracer in competition receptor-binding assays to study the interaction of these receptors with their ligands. As shown in Figure 7, the competitive binding data on human RXFP3, RXFP4, and RXFP1 were all typical sigmoidal curves when DOTA/Eu ${ }^{3+}$-labeled relaxin-3 was used as tracer, suggesting that the 
DOTA/Eu ${ }^{3+}$-lableled relaxin-3 was suitable for monitoring the binding of these receptors with their ligands. The calculated pIC50 values for relaxin-3 binding on RXFP3 and RXFP4 were $8.05 \pm 0.07$ and $8.04 \pm 0.04$ respectively when the indicated concentration of DOTA/Eu ${ }^{3+}$-labeled relaxin-3 tracer was used in the competition assays. The calculated pIC50 values for human relaxin-2 (H2 relaxin) and human relaxin-3 (H3 relaxin) binding on human RXFP1 were $8.83 \pm 0.17$ and $7.93 \pm 0.20$ respectively, indicating that relaxin-2 had $\sim 10$-fold higher RXFP1-binding affinity than relaxin-3.

\section{Discussion}

In the present work, we developed an efficient approach for site-specific labeling of recombinant relaxin-3 by which various functional probes could be site-specifically introduced to the A-chain $\mathrm{N}$-terminus of the recombinant human relaxin-3. The labeling approach is based on three major sequential steps: i), reversible primary-amine blockage of a designed precursor; ii), release of a new $\mathrm{N}$-terminus through enzymatic removal of the designed pro-fragment; iii), irreversible modification of the newly released $\mathrm{N}$-terminus by a functional probe or a suitable adaptor and subsequent removal of the reversible blockage. This approach could also be used for site-specific labeling of other recombinant peptides and proteins after slight modification. To introduce $\mathrm{Eu}^{3+}$ to the newly released A-chain $\mathrm{N}$-terminus of human relaxin-3, we tried several methods. First, we used DTPA dianhydrate that is very active to primary amines. Unfortunately, the DTPA-modified relaxin-3 always had a molecular mass increase of 53 although we tried various modification conditions. The unexpected molecular mass increase was likely caused by modification of the DTPA moiety since the modified peptide lost $\mathrm{Eu}^{3+}$-binding ability. This phenomenon was also observed in europium-labeling of the chemically synthesized INSL3 (Shabanpoor et al. 2008). Thereafter, we used $\mathrm{Eu}^{3+}$-preloaded SCN-Bn-DTPA to modify the newly released A-chain N-terminus. However, the modification efficiency was quite low although the modified peptide had the correct 
molecular mass. This was probably due to the low reactivity of the SCN-moiety to primary amines. Finally, we tried a two-step procedure: introduction of an alkyne moiety through reaction with $\mathrm{N}$-hydroxysuccinimide ester and subsequent introduction of DOTA-bound $\mathrm{Eu}^{3+}$ through click chemistry. This two-step procedure worked well and DOTA/Eu ${ }^{3+}$-labeled relaxin-3 was obtained in good overall yield. The two-step labeling procedure also introduced a long hydrophilic arm between the peptide and the DOTA/Eu ${ }^{3+}$ probe. We expected that the long hydrophilic arm would be helpful for the activity of the labeled peptide due to the elimination of steric hindrance. Although a large DOTA/Eu ${ }^{3+}$-moiety was introduced, the labeled relaxin-3 retained most of the binding affinity for RXFP3, RXFP4, and RXFP1, its measured $\mathrm{K}_{\mathrm{d}}$ values being only slightly lower than those of ${ }^{125}$ I-labeled relaxin-3 (Liu et al. 2003b; Sudo et al. 2003; Liu et al. 2003a). The positioning of the DOTA/Eu ${ }^{3+}$-moiety at the end of the A-chain is therefore appropriate for retaining high affinity for all the receptors and is consistent with the NMR solution structure of relaxin-3 (Rosengren et al., 2006) which shows that the N-terminus of the A-chain is on the opposite side of the peptide from the receptor interacting residues in the B-chain. Considering the superior stability of the DOTA/Eu ${ }^{3+}$-labeled relaxin- 3 to the ${ }^{125}$ I-labeled peptide, the DOTA/Eu ${ }^{3+}$-labeled relaxin-3 tracer was a good choice in the ligand-receptor interaction assays. As shown in Figure 7, the DOTA/Eu ${ }^{3+}$-labeled relaxin-3 could monitor the ligand binding with three receptors (RXFP3, RXFP4, and RXFP1) and could discriminate the binding affinities of different ligands with one receptor.

For lanthanide labeling, a metal ion chelator is needed to be covalently attached to the target protein/peptide. In general, DTPA or DTTA, that have moderate binding affinity with lanthanides, are used since the bound lanthanide needs to be dissociated in the subsequent TRF measurement. Therefore, tight lanthanide chelators, such as DOTA, are rarely used for lanthanide-labeling and subsequent TRF assay. Recently, a procedure for TRF measurement of the DOTA-bound europium was reported (De Silva et al. 2010). However, we found that the reported neutralizing procedure showed poor reproducibility due to lack of buffering capacity. So we further improved the TRF measurement procedure for DOTA-bound europium and setup a robust assay 
system that showed good reproducibility. Since the DOTA/Eu ${ }^{3+}$-labeled peptide could be eluted from rp-HPLC by the conventionally used acidic solvents (containing $\sim 0.1 \%$ of TFA) without europium loss, DOTA/Eu ${ }^{3+}$-labeling had advantage over the conventionally used DTPA/Eu ${ }^{3+}$ - and DTTA/ $\mathrm{Eu}^{3+}$-labeling that had to be eluted by neutral solvents. Our successful TRF measurement of the DOTA-bound europium now allows DOTA/lanthanide-labeling to be widely used for protein/peptide labeling in future.

Acknowledgements This work was supported by the National Natural Science Foundation of China (30970609) and the National Basic Research Program of China (973 Program, no. 2010CB912604). Part of this research was funded by NHMRC (Australia) project grants 350284,508995 to JDW and RADB. We are grateful to Tania Ferraro \& Sharon Layfield for assistance with biochemical assays. The studies at the FNI were supported by the Victorian Government's Operational Infrastructure Support Program.

\section{References}

Banerjee A, Shen PJ, Ma S, Bathgate RA, Gundlach AL (2010) Swim stress excitation of nucleus incertus and rapid induction of relaxin-3 expression via CRF1 activation. Neuropharmacology 58:145-155

Bathgate RA, Samuel CS, Burazin TC, Layfield S, Claasz AA, Reytomas IG, Dawson NF, Zhao C, Bond C, Summers RJ, Parry LJ, Wade JD, Tregear GW (2002) Human relaxin gene $3(\mathrm{H} 3)$ and the equivalent mouse relaxin (M3) gene: novel members of the relaxin peptide family. J Biol Chem 277:1148-1157

Burazin TC, Bathgate RA, Macris M, Layfield S, Gundlach AL, Tregear GW (2002) Restricted, but abundant, expression of the novel rat gene-3 (R3) relaxin in the dorsal tegmental region of brain. J Neurochem 82:1553-1557 
De Silva CR, Vagner J, Lynch R, Gillies RJ, Hruby VJ (2010) Optimization of time-resolved fluorescence assay for detection of Eu-DOTA-labeled ligand-receptor interactions. Anal Biochem 398:15-23

Hida T, Takahashi E, Shikata K, Hirohashi T, Sawai T, Seiki T, Tanaka H, Kawai T, Ito O, Arai T, Yokoi A, Hirakawa T, Ogura H, Nagasu T, Miyamoto N, Kuromitsu J (2006) Chronic intracerebroventricular administration of relaxin-3 increases body weight in rats. J Recept Signal Transduct Res 26:147-158

Hsu SY, Nakabayashi K, Nishi S, Kumagai J, Kudo M, Sherwood OD, Hsueh AJ (2002) Activation of orphan receptors by the hormone relaxin. Science 295:671-674

Kolb HC, Finn MG, Sharpless KB (2001) Click chemistry: diverse chemical function from a few good reactions. Angew Chem Int Ed Engl 40:2004-2021

Liu C, Chen J, Sutton S, Roland B, Kuei C, Farmer N, Sillard R, Lovenberg TW (2003a) Identification of relaxin-3/INSL7 as a ligand for GPCR142. J Biol Chem 278:50765-50770

Liu C, Eriste E, Sutton S, Chen J, Roland B, Kuei C, Farmer N, Jörnvall H, Sillard R, Lovenberg TW (2003b) Identification of relaxin-3/INSL7 as an endogenous ligand for the orphan G-protein-coupled receptor GPCR135. J Biol Chem 278:50754-50764

Liu C, Kuei C, Sutton S, Chen J, Bonaventure P, Wu J, Nepomuceno D, Kamme F, Tran DF, Zhu J, Wilkinson T, Bathgate R, Eriste E, Sillard R, Lovenberg TW (2005) INSL5 is a high affinity specific agonist for GPCR142 (GPR100). J Biol Chem 280:292-300

Luo X, Liu YL, Layfield S, Shao XX, Bathgate RA, Wade JD, Guo ZY (2010) A simple approach for the preparation of mature human relaxin-3. Peptides 31:2083-2088

Ma S, Sang Q, Lanciego JL, Gundlach AL (2009) Localization of relaxin-3 in brain of Macaca fascicularis: identification of a nucleus incertus in primate. J Comp Neurol 517:856-872 
McGowan BM, Stanley SA, Donovan J, Thompson EL, Patterson M, Semjonous NM, Gardiner JV, Murphy KG, Ghatei MA, Bloom SR (2008) Relaxin-3 stimulates the hypothalamic-pituitary-gonadal axis. Am J Physiol Endocrinol Metab 295:E278-286

McGowan BM, Stanley SA, Smith KL, Minnion JS, Donovan J, Thompson EL, Patterson M, Connolly MM, Abbott CR, Small CJ, Gardiner JV, Ghatei MA, Bloom SR (2006) Effects of acute and chronic relaxin-3 on food intake and energy expenditure in rats. Regul Pept 136:72-77

McGowan BM, Stanley SA, White NE, Spangeus A, Patterson M, Thompson EL, Smith KL, Donovan J, Gardiner JV, Ghatei MA, Bloom SR (2007) Hypothalamic mapping of orexigenic action and Fos-like immunoreactivity following relaxin-3 administration in male Wistar rats. Am $\mathbf{J}$ Physiol Endocrinol Metab 292:E913-919

McGowan BM, Stanley SA, Smith KL, White NE, Connolly MM, Thompson EL, Gardiner JV, Murphy KG, Ghatei MA, Bloom SR (2005) Central relaxin-3 administration causes hyperphagia in male Wistar rats. Endocrinology $146: 3295-3300$

Rosengren KJ, Lin F, Bathgate RA, Tregear GW, Daly NL, Wade JD, Craik DJ (2006) Solution structure and novel insights into the determinants of the receptor specificity of human relaxin-3. J Biol Chem 281:5845-5851

Selvin PR (2002) Principles and biophysical applications of lanthanide-based probes. Annu Rev Biophys Biomol Struct 31:275-302

Shabanpoor F, Hughes RA, Bathgate RA, Zhang S, Scanlon DB, Lin F, Hossain MA, Separovic F, Wade JD (2008) Solid-Phase Synthesis of Europium-Labeled Human INSL3 as a Novel Probe for the Study of Ligand-Receptor Interactions. Bioconjugate Chem 19:1456-1463

Shabanpoor F, Separovic F, Wade JD (2009) The human insulin superfamily of polypeptide hormones. Vitam Horm 80:1-31 
Silvertown JD, Neschadim A, Liu HN, Shannon P, Walia JS, Kao JC, Robertson J, Summerlee AJ, Medin JA (2010) Relaxin-3 and receptors in the human and rhesus brain and reproductive tissues. Regul Pept 159:44-53

Smith CM, Hosken IT, Sutton SW, Lawrence AJ, Gundlach AL (2011a) Relaxin-3 null mutation mice display a circadian hypoactivity phenotype. Genes Brain Behav, published online, doi: 10.1111/j.1601-183X.2011.00730.x

Smith CM, Lawrence AJ, Sutton SW, Gundlach AL (2009a) Behavioral phenotyping of mixed background (129S5:B6) relaxin-3 knockout mice. Ann N Y Acad Sci 1160:236-241

Smith CM, Ryan PJ, Hosken IT, Ma S, Gundlach AL (2011b) Relaxin-3 systems in the brain-The first 10 years. J Chem Neuroanat, published online.

Smith CM, Shen PJ, Ma S, Sutton SW, Gundlach AL (2009b) Verification of a relaxin-3 knockout/LacZ reporter mouse as a model of relaxin-3 deficiency. Ann N Y Acad Sci 1160:259-260

Sudo S, Kumagai J, Nishi S, Layfield S, Ferraro T, Bathgate RA, Hsueh AJ (2003) $\mathrm{H} 3$ relaxin is a specific ligand for LGR7 and activates the receptor by interacting with both the ectodomain and the exoloop 2. J Biol Chem 278:7855-7862

Tanaka M (2010) Relaxin-3/insulin-like peptide 7, a neuropeptide involved in the stress response and food intake. FEBS J 277:4990-4997

Tanaka M, Iijima N, Miyamoto Y, Fukusumi S, Itoh Y, Ozawa H, Ibata Y (2005) Neurons expressing relaxin 3/INSL 7 in the nucleus incertus respond to stress. Eur J Neurosci 21:1659-1670

Watanabe Y, Miyamoto Y, Matsuda T, Tanaka M (2011a) Relaxin-3/INSL7 regulates the stress-response system in the rat hypothalamus. J Mol Neurosci 43:169-174 
Watanabe Y, Tsujimura A, Takao K, Nishi K, Ito Y, Yasuhara Y, Nakatomi Y, Yokoyama C, Fukui K, Miyakawa T, Tanaka M (2011b) Relaxin-3-deficient mice showed slight alteration in anxiety-related behavior. Front Behav Neurosci 5:50 
Fig. 1 a The amino acid sequence of the recombinant human relaxin-3 precursor. b The amino acid sequence of the mature recombinant human relaxin-3. $\mathbf{c}$ The proposed site-specific human relaxin-3 labeling strategy. The A-chain of human relaxin-3 is shown in green, the B-chain is shown in red and the linker peptide is shown in black. The cysteine residues are shown as filled circles (in $\mathbf{a}$ and $\mathbf{b}$ ) and the disulfide bonds are shown as sticks (in $\mathbf{a}$ and $\mathbf{b}$ ) or as dashes (in $\mathbf{c}$ ).

Fig. 2 HPLC analysis of the human relaxin-3 precursor after Aeromonas aminopeptidase digestion. After digestion, $2 \mu \mathrm{l}$ of the digestion mixture $(\sim 10 \mu \mathrm{g}$ peptide) was removed, acidified by TFA, and applied to analytical C18 rp-HPLC that was eluted by an acidic acetonitrile gradient. The eluted peptide peak (indicated by a star) was manually collected, lyophilized, and subjected to mass spectrometry analysis. The expected mass value was listed in the parenthesis.

Fig. 3 HPLC analysis of the two-chain relaxin-3 carrying an alkyne-moiety at the A-chain N-terminus. The single-chain relaxin-3 (without $6 \times$ His-tag) was sequentially subjected to reversible blocking, Asp-N digestion, acetylene-PEG4-NHS ester modification, and deblocking. After the sequential treatment, $100 \mu \mathrm{l}(\sim 10 \mu \mathrm{g}$ peptide $)$ of the deblocking mixture was applied to analytical C18 rp-HPLC that was eluted by an acidic acetonitrile gradient. The eluted peptide peak (indicated by a star) was manually collected, lyophilized, and subjected to mass spectrometry analysis. The expected mass value was listed in the parenthesis.

Fig. 4 HPLC (a) and mass spectrometry (b) analyses of the human relaxin-3 labeled by the DOTA-bound europium ion. The two-chain relaxin-3 carrying an alkyne-moiety was reacted with the europium-loaded azido-mono-amide-DOTA at 20 ${ }^{\circ} \mathrm{C}$ overnight. After cycloaddition, $2 \mu$ of the reaction mixture $(\sim 10 \mu \mathrm{g}$ peptide $)$ was applied to analytical C18 rp-HPLC that was eluted by an acidic acetonitrile gradient. The eluted peptide peak (indicated by a star) was manually collected, lyophilized, and subjected to mass spectrometry analysis. The expected molecular mass was listed in 
the parenthesis.

Fig. 5 The time-resolved fluorescence measurement of the DOTA/ $\mathrm{Eu}^{3+}$-labeled relaxin-3 using our improved neutralization procedure. Open circle, 0.1 pmole of europium standard was directly mixed with $200 \mu \mathrm{l}$ of enhancer solution. Filled circle, 0.1 pmole of europium standard was subjected to sequential acidification and neutralization before addition of $150 \mu \mathrm{l}$ enhancer solution. Open square, europium-labeled relaxin-3 ( 0.1 pmole estimated from HPLC pear area) was directly mixed with $200 \mu \mathrm{l}$ of enhancer solution. Filled square, europium-labeled relaxin-3 ( $\sim 0.1$ pmole estimated from HPLC pear area) was subjected to sequential acidification and neutralization before addition of $150 \mu \mathrm{l}$ enhancer solution. After mixed, the TRF was measured on a Spectramax M5 plate reader at different times. The data were shown as mean $\pm \mathrm{SD}, \mathrm{n}=3$.

Fig. 6 Saturation binding of the DOTA/Eu ${ }^{3+}$-labeled human relaxin-3 on human RXFP3 (a), human RXFP4 (b), and human RXFP1 (c). The data were expressed as mean $\pm \mathrm{SD}(\mathrm{n}=3)$. The measured data were fitted by a hyperbolic ligand-receptor binding function $\mathrm{Y}=\mathrm{B}_{\max } \mathrm{X} /\left(\mathrm{K}_{\mathrm{d}}+\mathrm{X}\right)$ using the software SigmaPlot 10.0. The linear Scatchard plots were shown in the inner panels. The non-specific binding was $~ 20 \%$ of total binding for RXFP3, 30\% for RXFP4, and 50\% for RXFP1.

Fig. 7 Competition receptor binding assays on human RXFP3 (a), human RXFP4 (b), and human RXFP1 (c) using the DOTA/Eu ${ }^{3+}$-labeled relaxin-3 as tracer. The measured data were shown as mean \pm SD $(n=3)$, and fitted by the software SigmaPlot 10.0 . 

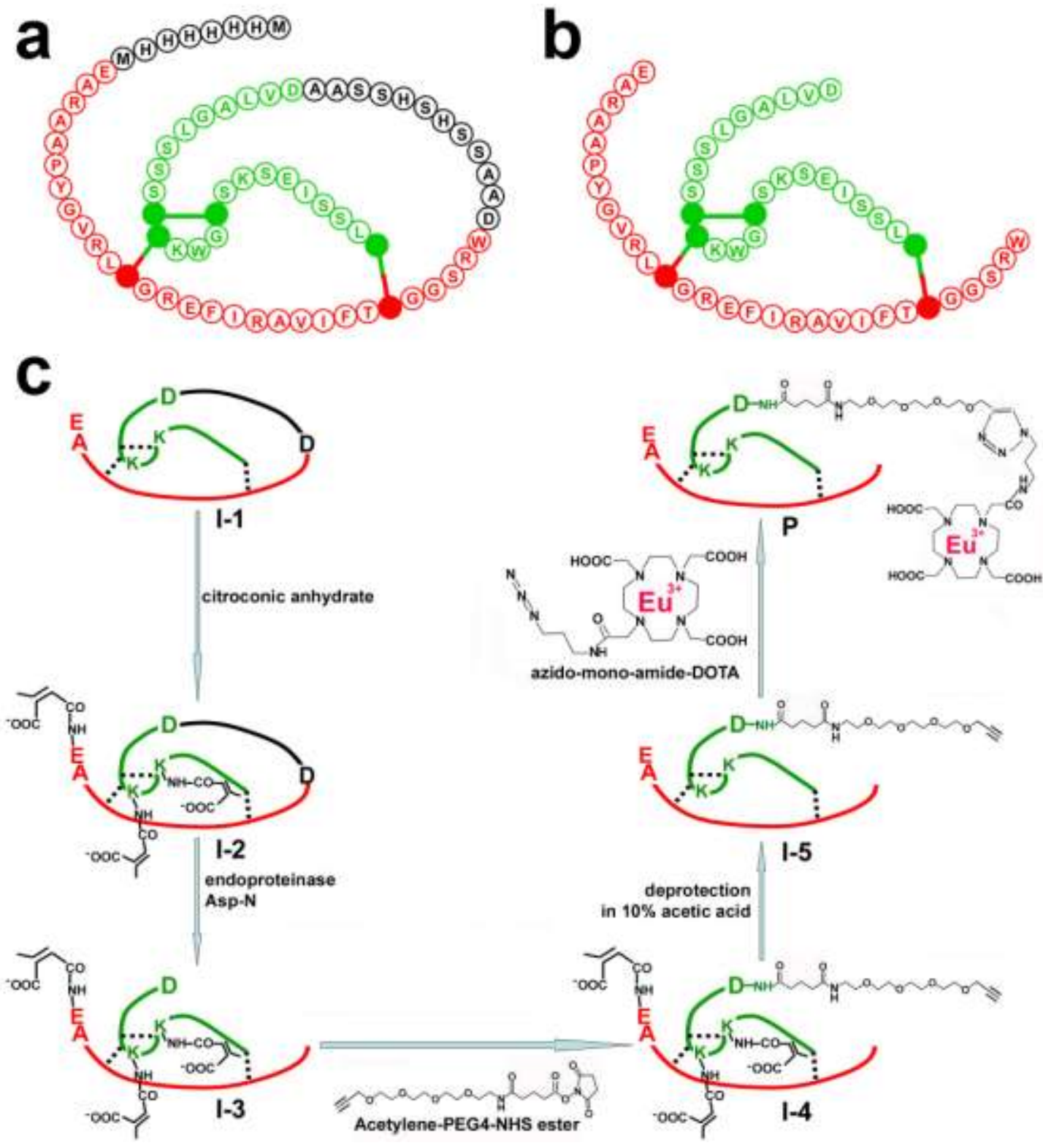

Fig. 1 


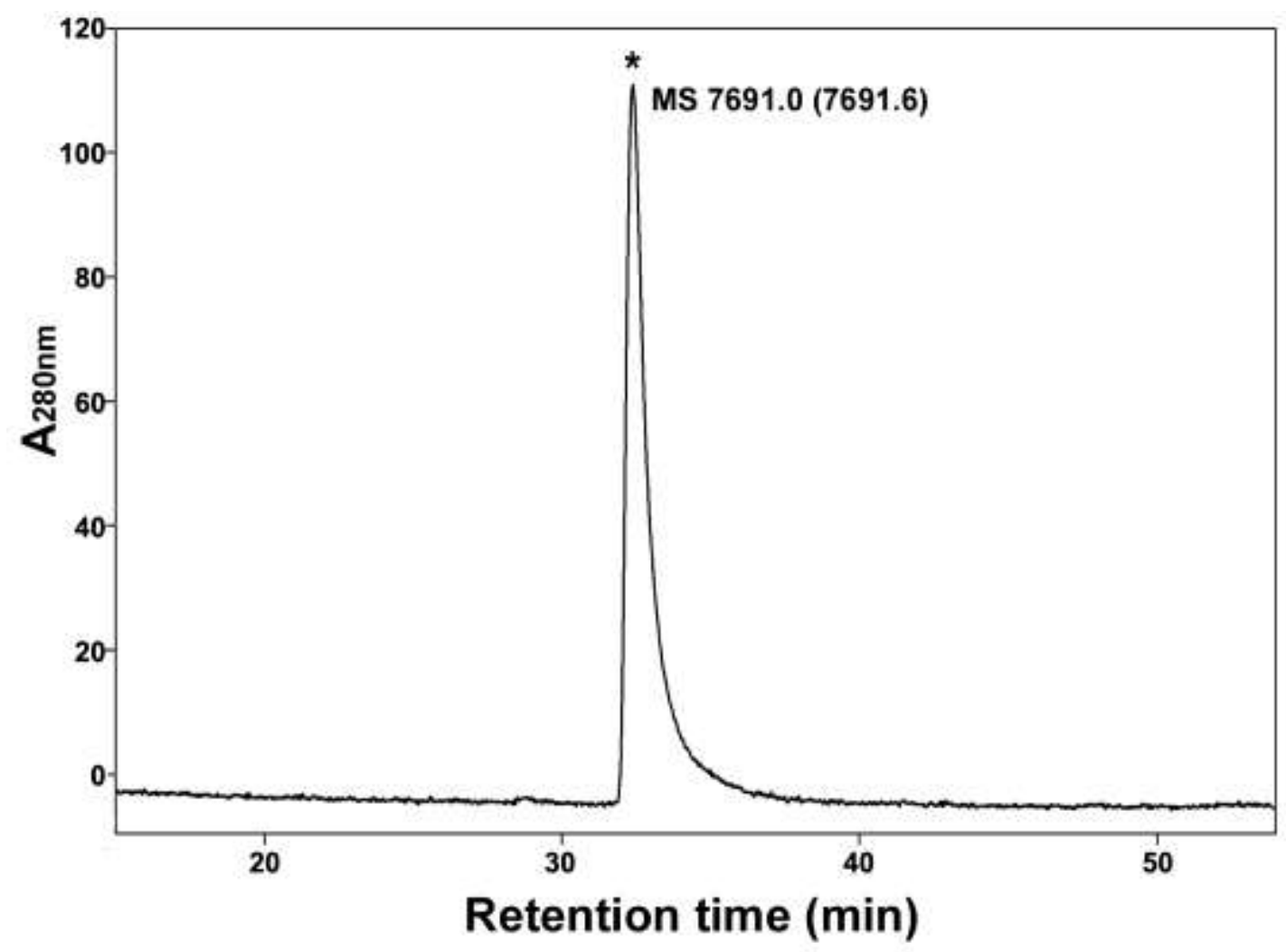

Fig. 2 


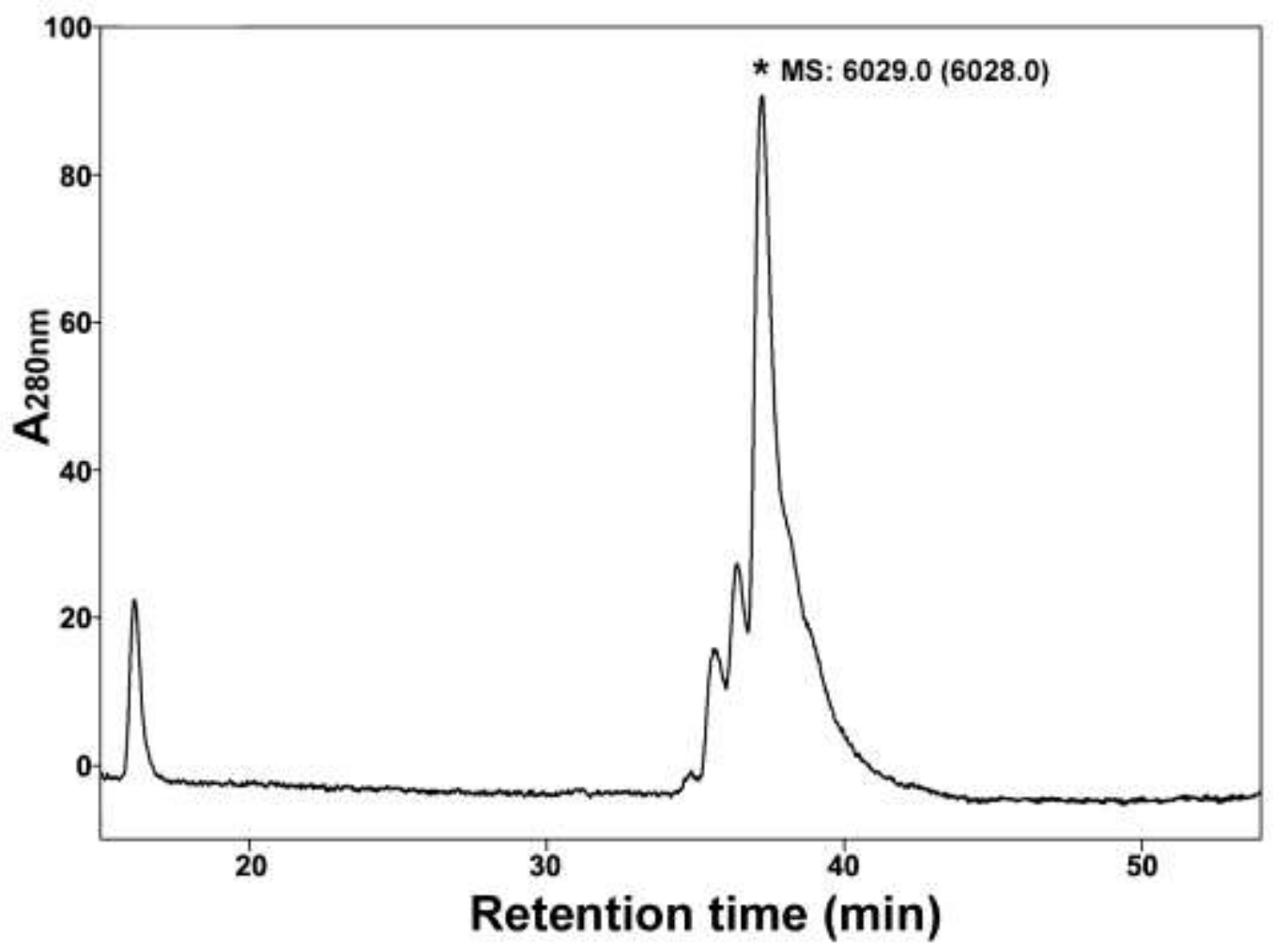

Fig. 3 

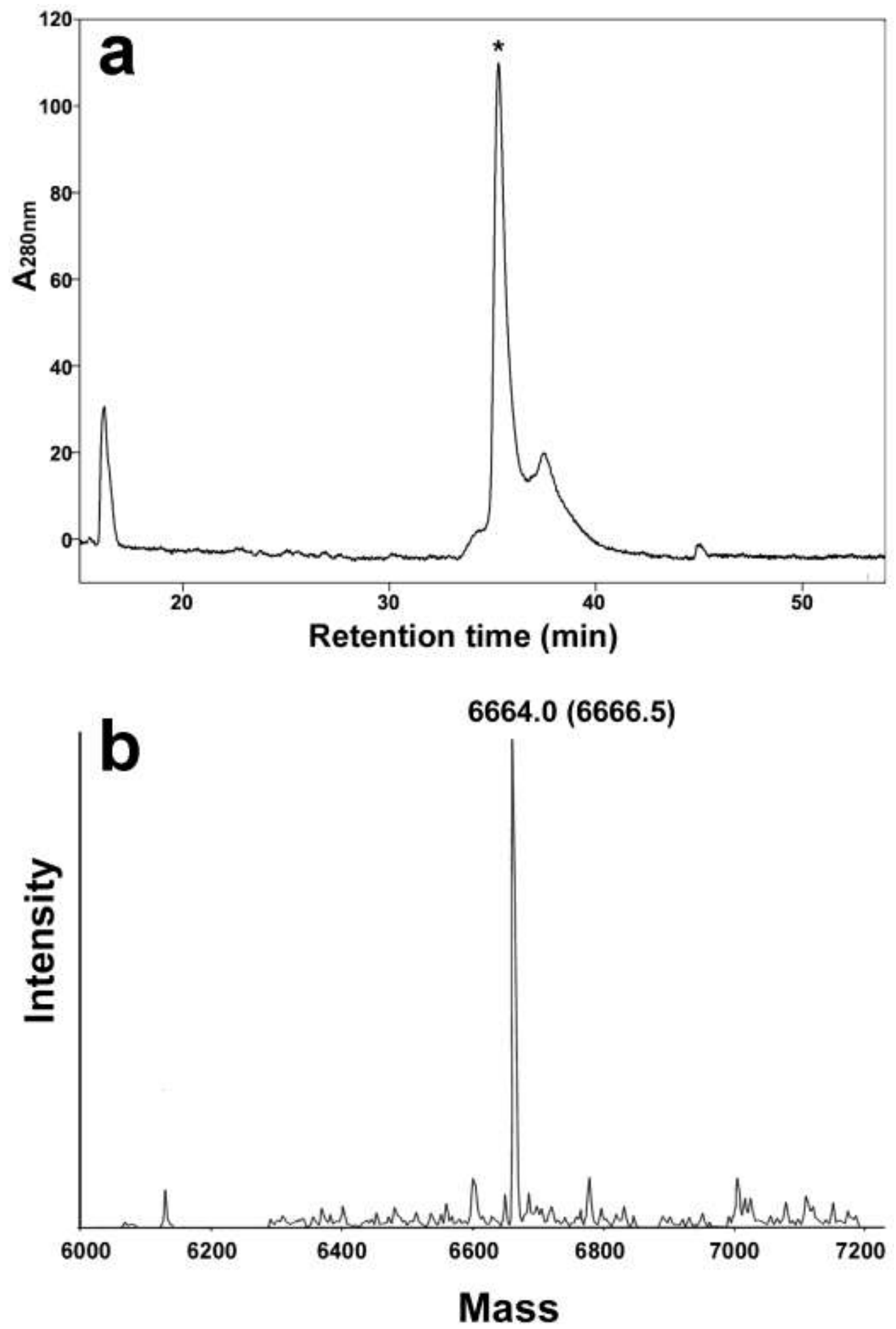

Fig. 4 


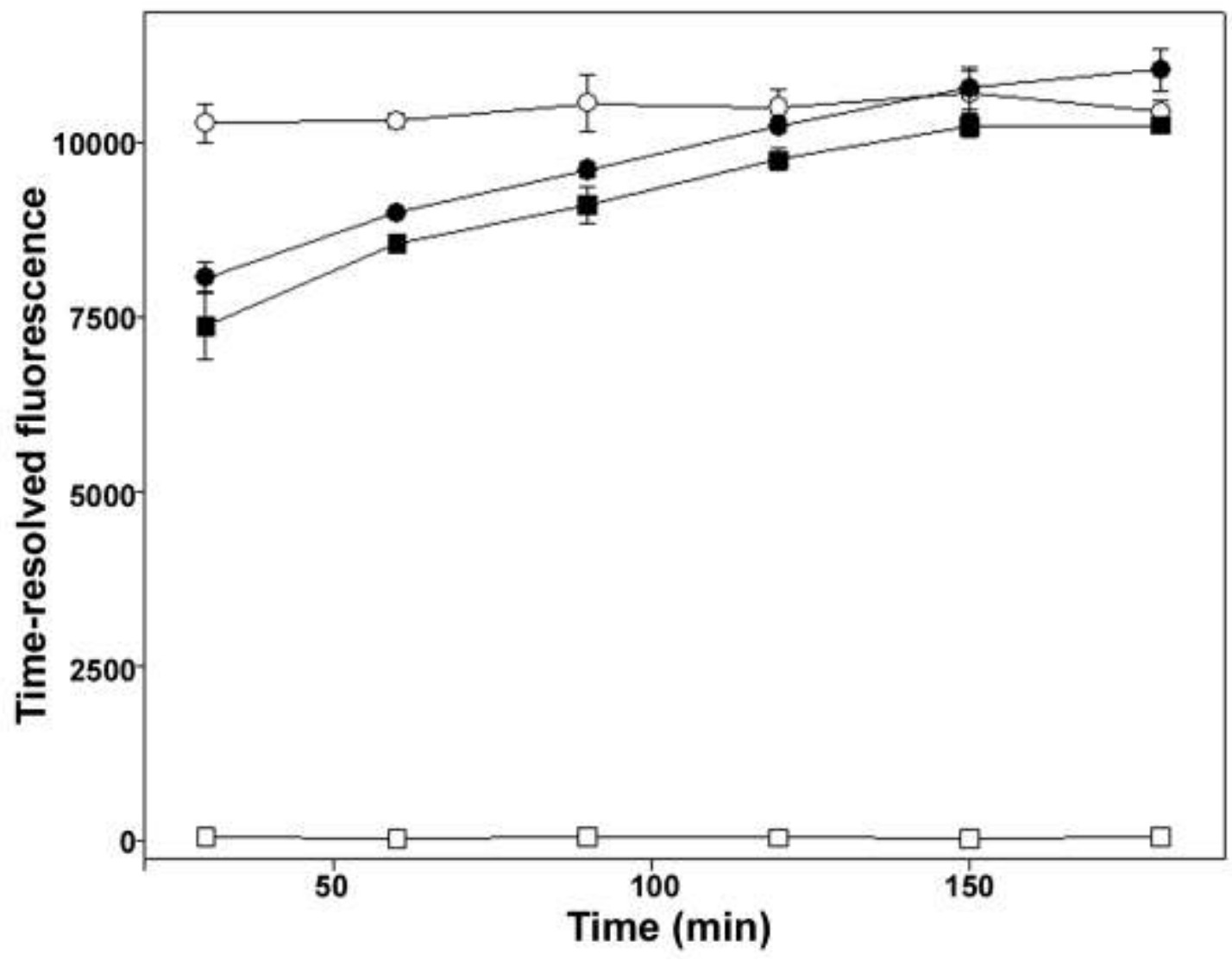

Fig. 5 

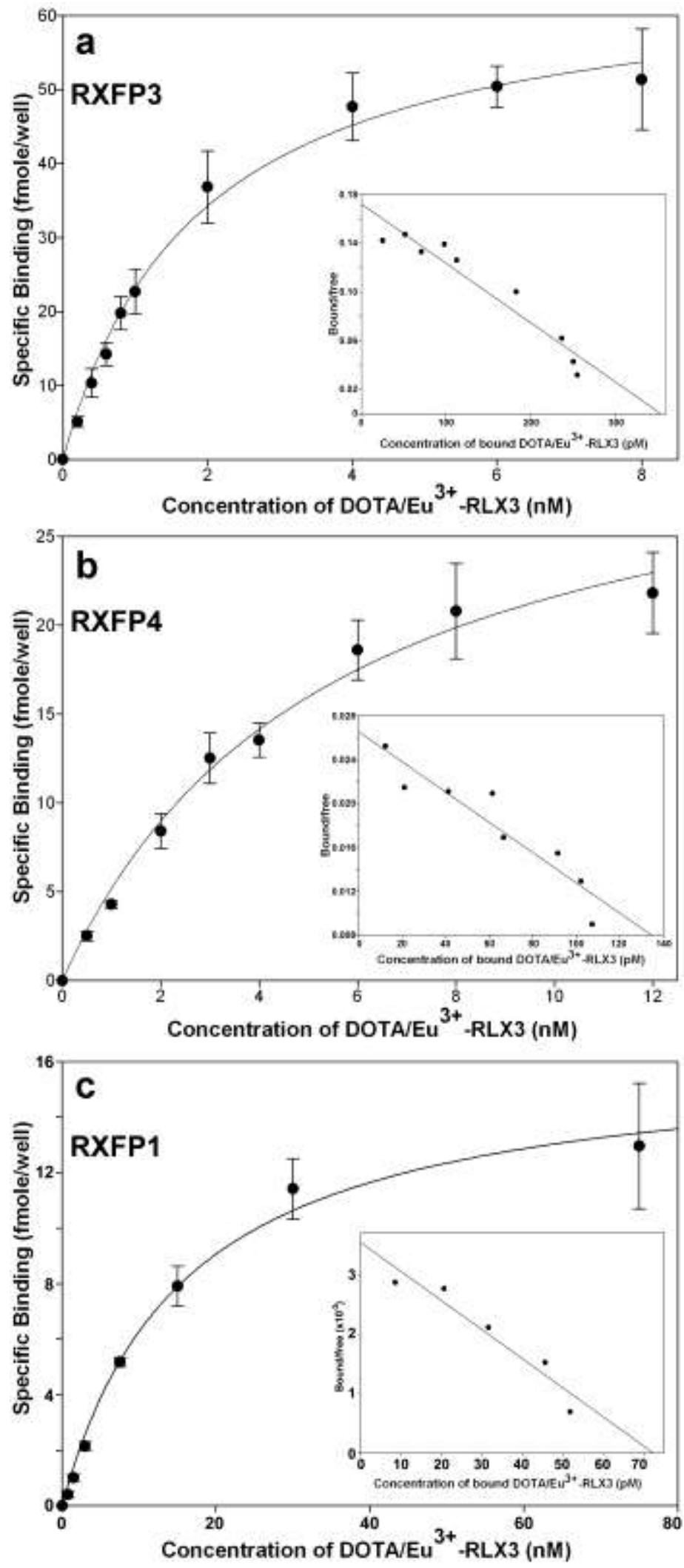

Fig. 6 

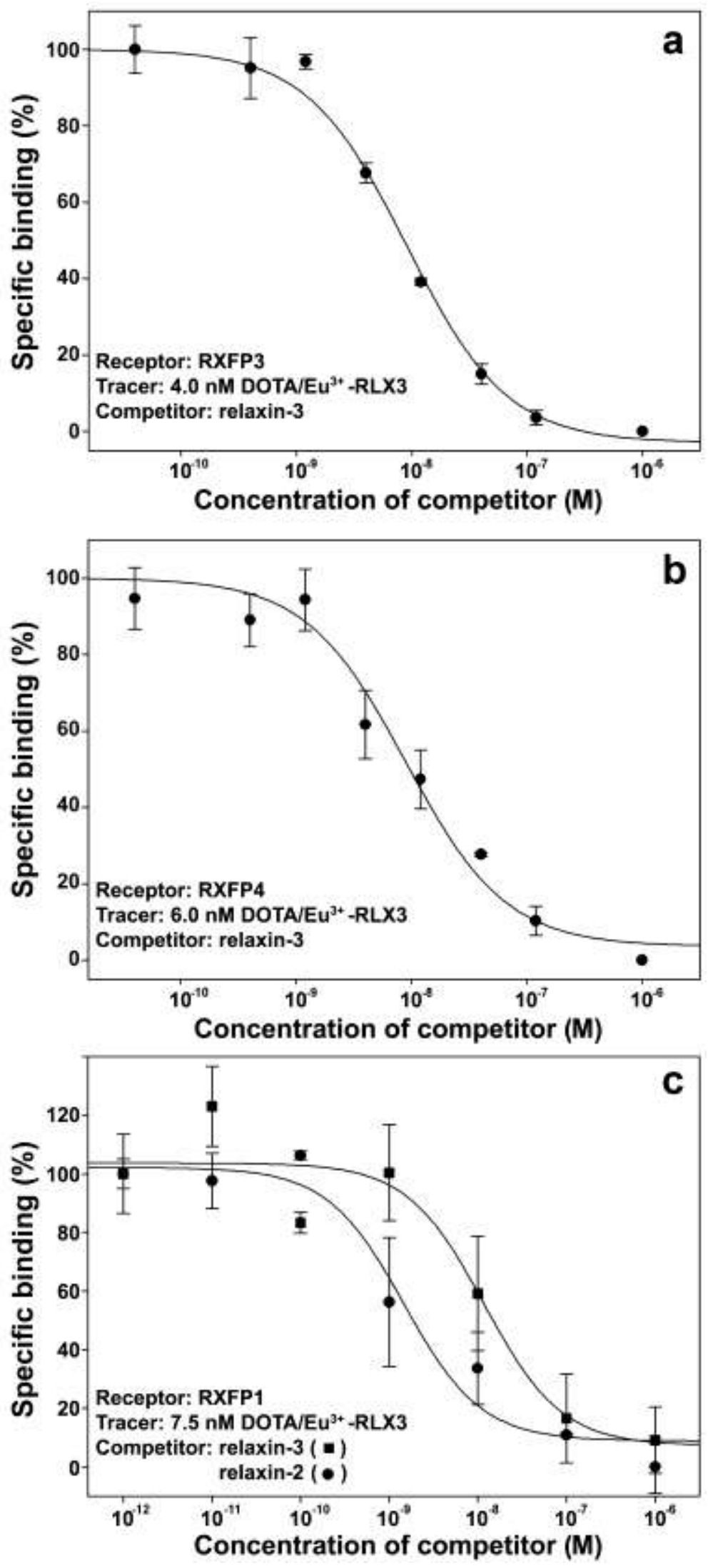

Fig. 7 